\title{
Synthesis and Photochromism of Some Mono and Bis (Thienyl) Substituted Oxathiine 2,2-dioxides ${ }^{\dagger}$
}

\author{
Stuart Aiken, Christopher D. Gabbutt, B. Mark Heron*, Craig R. Rice \\ and Dimitrios Zonidis* \\ Department of Chemical Sciences, School of Applied Sciences, University of Huddersfield, \\ Queensgate, Huddersfield, HD1 3DH, UK
}

Abstract: 1,2-Oxathiine 2,2-dioxides have been obtained from their respective 3,4-dihydro-4dimethylamino precursors, for the first time, by a mild Cope elimination of the 4dimethylamino function. The application of the 1,2-oxathiine 2,2-dioxide scaffold in materials chemistry is exemplified by the efficient P-type photochromism of the 5,6-bis(2,5-dimethyl-3thienyl) substituted oxathiine 2,2-dioxides.

P-type photochromic dithienylethenes such as 1-open, which readily undergoes reversible conversion to the coloured isomer 1-closed, (Scheme 1) are fundamental switching units which have been used to modulate a variety of physical and optical properties. ${ }^{1}$ Structural variation of the essential 1,2-bis(2,5-dimethylthiophen-3-yl)ethene core has been frequently explored by modification of the 2,5-dimethylthiophene moiety ${ }^{1,2}$ and to a somewhat lesser extent by variation of the perfluorocycle, particularly replacement of the latter with a 5-membered heterocyclic unit to afford $\mathbf{2}$, wherein the heterocycle has been selected from imidazole, ${ }^{3,4}$ imidazolium, ${ }^{5}$ pyrrole, ${ }^{6}$ thienophosphole ${ }^{7}$ phosphindolothiophene ${ }^{8}$ thiophene, ${ }^{9-11}$ thiopyranothiophene, ${ }^{12}$ silole $,{ }^{13,14} 1,3$-dithiole ${ }^{15}$ and thiazole ${ }^{16}$ and less commonly with a sixmembered unit leading to $\mathbf{2}$ where the heterocyclic unit includes quinoxaline, ${ }^{17}$ triazoloquinoline,${ }^{18}$ pyridazine,${ }^{19}$ thiazine $,{ }^{20} 1,2$-oxazine ${ }^{21}$ and $1,2,4$-triazine. ${ }^{22}$
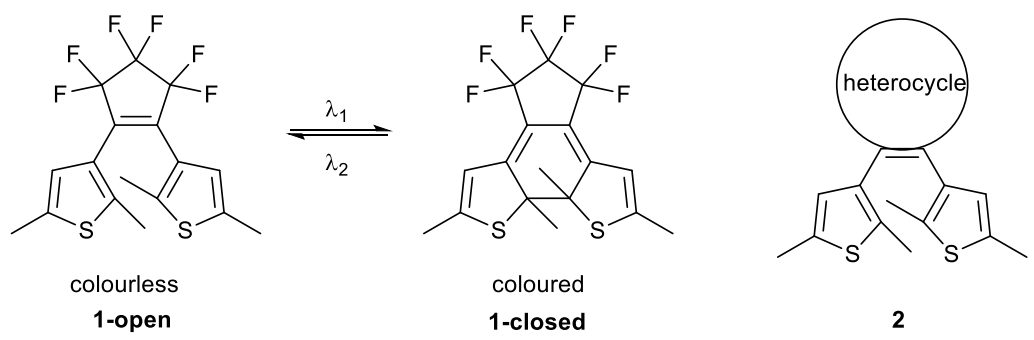

Scheme 1 Representative photochromic response of a dithienylethene system

We have previously studied the synthesis and performance of various T-type photochromic systems, e.g. naphthopyrans ${ }^{23-25}$ and naphthoxazines, ${ }^{26,27}$ and we have recently explored negatively photochromic systems. ${ }^{28}$ In this study we describe the preliminary examples of an efficient synthetic route to the relatively little studied 1,2-oxathiine 2,2-dioxide unit and in doing so define a route to new photochromic dithienylethenes with a central 1,2-oxathiine 2,2dioxide core. This work constitutes part of our ongoing programme of heterocyclic synthesis concerning strategies to 1,2-oxathiine 2,2-dioxides in which we are exploring the versatility of sulfene additions to enaminoketones to afford relatively inaccessible substitution patterns on the 4-dimethylamino-3,4-dihydro-1,2-oxathiine 2,2-dioxide core and subsequent mechanistic 
investigations concerning the elimination of the 4-dimethylamino function to access diversely substituted unsaturated 1,2-oxathiine 2,2-dioxides. ${ }^{29}$

The addition of sulfenes to enaminoketones to afford 4-amino-3,4-dihydro-1,2-oxathiine 2,2dioxides has been explored by Schenone et al. ${ }^{30}$ Interestingly, the formation of the unsaturated 1,2-oxathiine 2,2-dioxides was a relatively scarcely observed feature in these initial studies. ${ }^{31}$ Indeed when chlorosulfene was added to an enaminoketone a subsequent facile base-promoted elimination of $\mathrm{HCl}$ was observed and the unsaturated 4-amino-1,2-oxathiine 2,2-dioxide resulted $^{32}$ and attempts to effect dehydrogenation of 4-amino-3,4-dihydro-1,2-oxathiine 2,2dioxides using excess DDQ met with variable results. ${ }^{33}$ We elected to utilise the foregoing sulfene addition chemistry ${ }^{30,34}$ and explore the subsequent elimination step required to obtain the unsaturated 1,2-oxathiine 2,2-dioxides. Fundamental to the present study was access to a series of methylene ketones and whilst deoxybenzoin $\mathbf{1 1}$ is widely commercially available the isomeric thienylketones $\mathbf{9}$ and $\mathbf{1 0}$ and the 1,2-bis(2,5-dimethylthiophen-3-yl)ethan-1-one $\mathbf{6}$ required preparation (Scheme 2). Examination of the literature revealed that the 2,5dimethylthienyl-3-acetic acid $\mathbf{4}$ has been prepared from 2,5-dimethylthiophene in three steps, acylation, Willgerodt-Kindler reaction and hydrolysis, in moderate overall yield. ${ }^{35}$ Given the unappealing nature of this sequence we elected to examine an alternative protocol. FriedelCrafts acylation of 2,5-dimethylthiophene with ethyl oxalyl chloride gave the glyoxalate $\mathbf{3}$ which underwent a smooth Wolff-Kishner reduction with concomitant hydrolysis to afford 4 in $64 \%$ yield (two-steps). The acid chloride 5 was prepared and used directly in a FriedelCrafts acylation with 2,5-dimethylthiophene to afford $6(47 \%)$ which displayed a characteristic singlet in its ${ }^{1} \mathrm{H}$ NMR spectrum at $\delta 3.92$ assigned to the methylene unit. Interestingly, applying this Friedel-Crafts strategy to benzene failed to afford $\mathbf{9}$ and instead $\mathbf{5}$ underwent a 'homo Friedel-Crafts' reaction followed by cyclisation to afford the novel thieno[3,4-c]pyranone 7 $\left(\delta_{\mathrm{CH}} 7.41 ; \delta_{\text {methylene }} 3.67 ; \delta_{\mathrm{C}=\mathrm{O}} 166.44\right)$; the geometry of which was established as the $Z$-isomer by a NOESY experiment. Evidently the thiophene moiety of $\mathbf{5}$ is more electron rich than benzene and is thus the favoured substrate in the foregoing acylation reaction. Undeterred by this setback, the Weinreb amide 8 ( $\left.\delta_{\mathrm{OMe}} 3.60 ; \delta_{\mathrm{NMe}} 3.18 ; \delta_{\text {methylene }} 3.59\right)$ was obtained $(65 \%)$ from 5 by standard methodology. ${ }^{36}$ The addition of $\mathrm{PhLi}$ to $\mathbf{8}$ proceeded without complication to afford target ketone $\mathbf{9}\left(\delta_{\text {methylene }} 4.12\right)$ in $66 \%$ yield (Scheme 2$)$. 


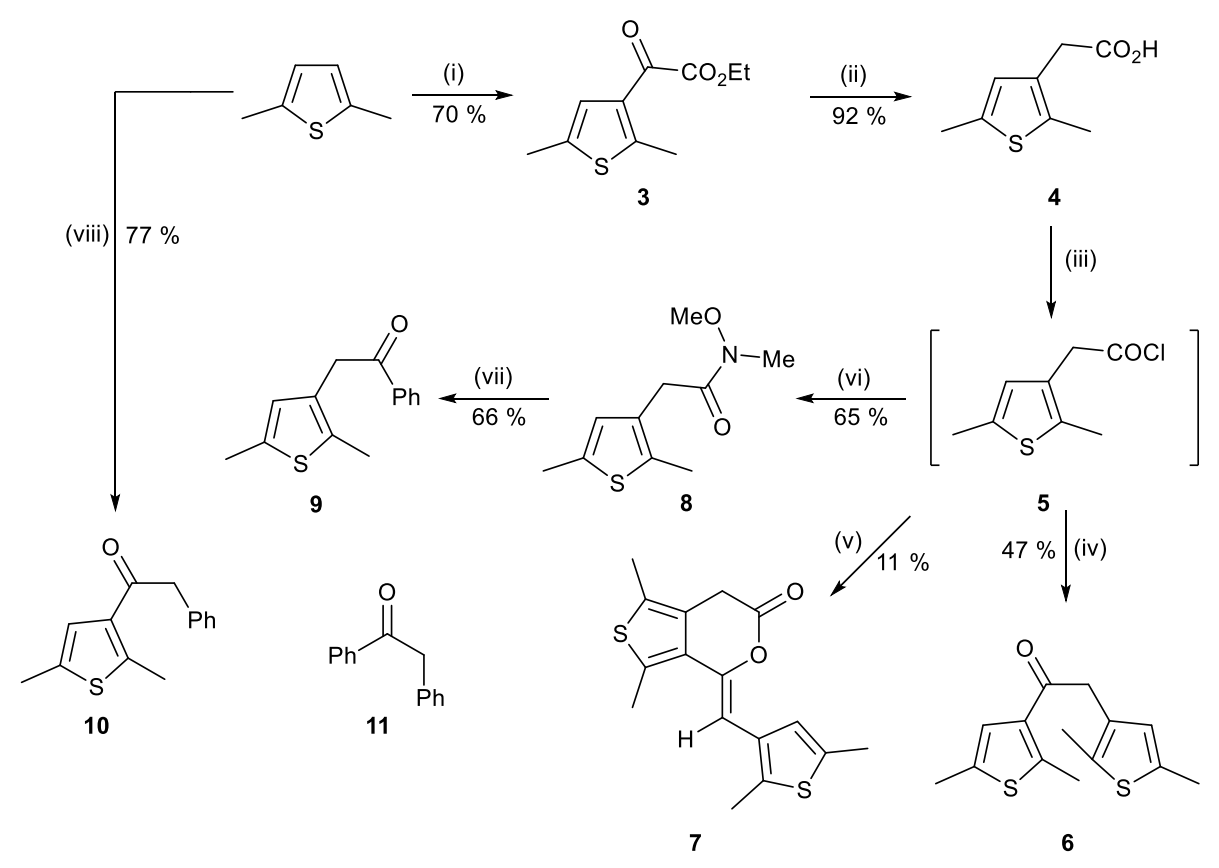

Reagents and conditions: (i) ethyl oxalyl chloride, $\mathrm{AlCl}_{3}$, anyhd., $\mathrm{MeNO}_{2}, 5^{\circ} \mathrm{C}-\mathrm{RT}$; (ii) $\mathrm{NH}_{2} \mathrm{NH}_{2} \cdot \mathrm{H}_{2} \mathrm{O}$, $\mathrm{HOCH}_{2} \mathrm{CH}_{2} \mathrm{OH}$, then $\mathrm{KOH}, 70{ }^{\circ} \mathrm{C}$ - reflux; (iii) $\mathrm{SOCl}_{2}$, cat. DMF, $\mathrm{CH}_{2} \mathrm{Cl}_{2}$; (iv) 2,5-dimethylthiophene, $\mathrm{AlCl}_{3}$, anyhd., $\mathrm{MeNO}_{2}, 5{ }^{\circ} \mathrm{C}-\mathrm{RT}$; (v) $\mathrm{PhH}, \mathrm{AlCl}_{3}$, anyhd., $\mathrm{MeNO}_{2}, 5^{\circ} \mathrm{C}-\mathrm{RT}$; (vi) MeNHOMe$\cdot \mathrm{HCl}$, pyridine, $\mathrm{CH}_{2} \mathrm{Cl}_{2}, 0-5^{\circ} \mathrm{C}-\mathrm{RT}$; (vii) $\mathrm{PhLi}$ in $\mathrm{Bu}_{2} \mathrm{O}$, anhyd., THF, $\mathrm{N}_{2},-78^{\circ} \mathrm{C}-\mathrm{RT}$; (viii) $\mathrm{PhCH}_{2} \mathrm{COCl}$, $\mathrm{AlCl}_{3}$, anyhd., $\mathrm{CH}_{2} \mathrm{Cl}_{2}, \mathrm{MeNO}_{2}, 5^{\circ} \mathrm{C}-\mathrm{RT}$

Scheme 2 Synthesis of thienyl ketones 6, 9 and $\mathbf{1 0}$

Ketone $\mathbf{1 0}$ was readily prepared by the Friedel-Crafts reaction of phenylacetyl chloride with 2,5-dimethylthiophene in $77 \%$ yield. Here the characteristic methylene singlet appeared at $\delta$ 4.11 in the ${ }^{1} \mathrm{H}$ NMR spectrum.

Ketones 6, 9-11 were transformed into their respective enaminoketones 12a - d $(60-86 \%$ yield) upon reaction with $N, N$-dimethylformamide dimethylacetal (DMFDMA) (Scheme 3). Phenylsulfene, generated in situ by the action of $\mathrm{Et}_{3} \mathrm{~N}$ on phenylmethanesulfonyl chloride, added cleanly to the foregoing enaminoketones to afford the 3,4-dihydro-1,2-oxathiine 2,2dioxides 13a-open - d-open $(53-77 \%)$ after either chromatography or recrystallization. Oxathiine 2,2-dioxide 13e-open was obtained in a similar manner in $55 \%$ yield from the addition of sulfene to 12a. The ${ }^{1} \mathrm{H}$ NMR spectrum of 13e-open revealed an AA'B spin pattern for the C-3 and C-4 hydrogens with $J_{3,4 \text { (trans) }}=9.1 \mathrm{~Hz}, J_{3^{\prime}, 4(\mathrm{cis})}=7.8 \mathrm{~Hz}$ and ${ }^{2} J_{3,3^{\prime}}=13.8 \mathrm{~Hz}$. 

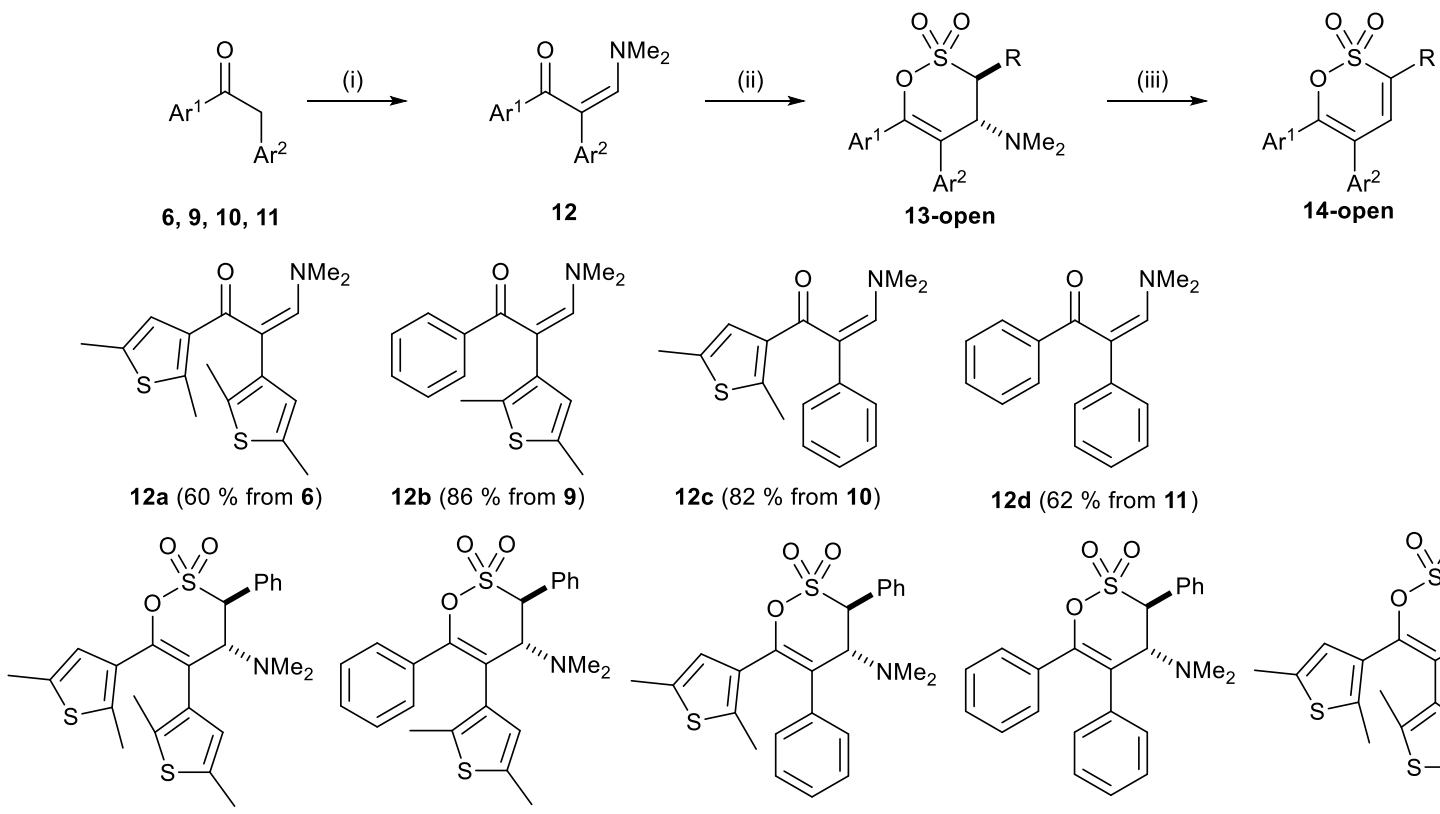

12c (82\% from 10$)$

12d (62 \% from 11)
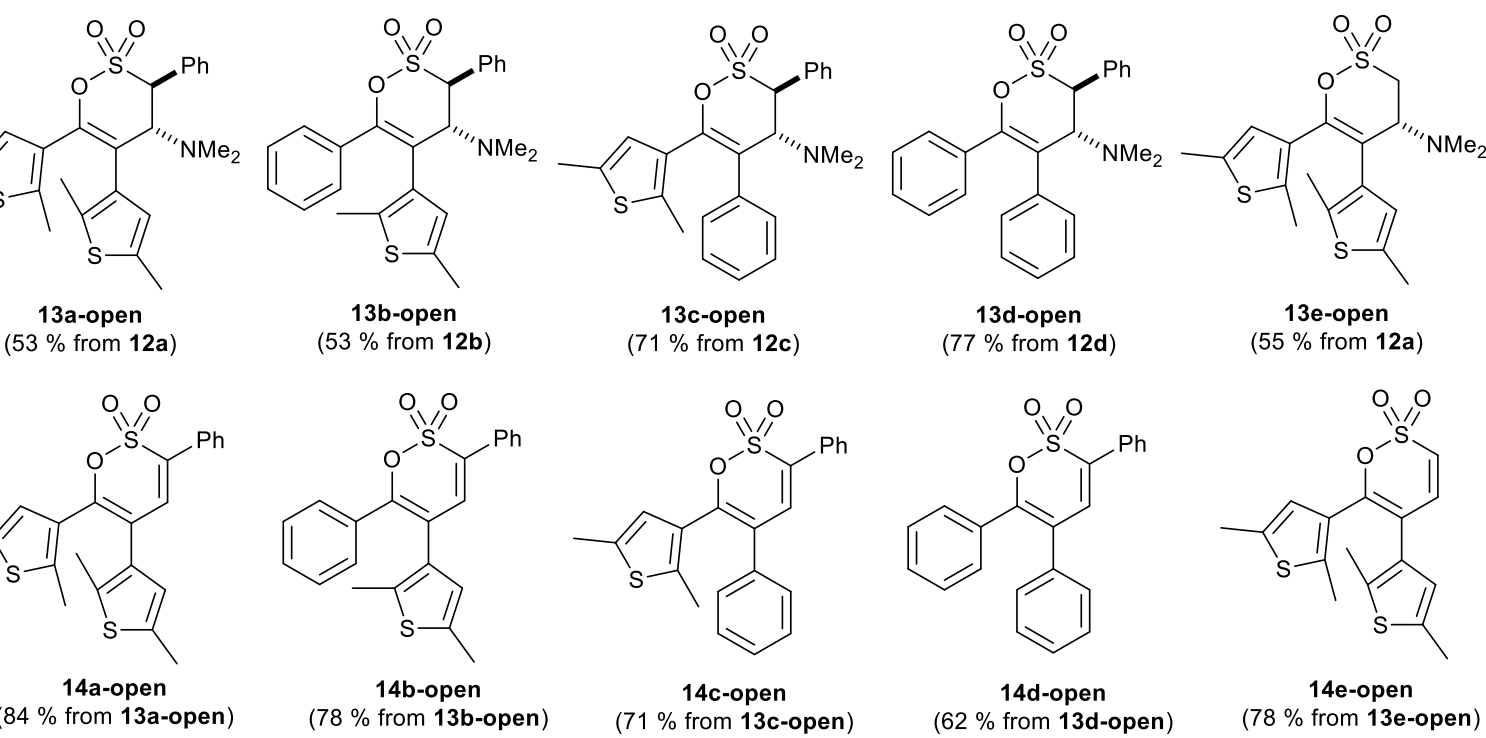

$(53 \%$ from $12 a)$

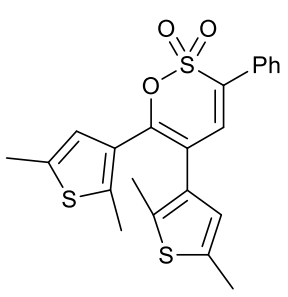

14a-open
(84 \% from 13a-open)
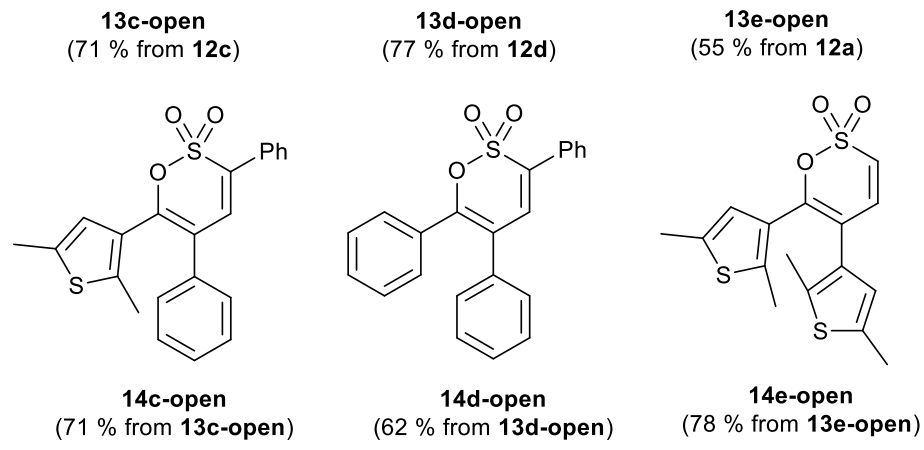

Reagents and conditions: (i) DMFDMA, reflux; (ii) either phenylmethanesulfonyl chloride (for 13a - d) or methanesulfonyl chloride (for $13 \mathrm{e}$ ), $\mathrm{Et}_{3} \mathrm{~N}$, anhyd. THF, $0{ }^{\circ} \mathrm{C}-\mathrm{RT}$; (iii) $m-\mathrm{CPBA}, \mathrm{CH}_{2} \mathrm{Cl}_{2}, 0^{\circ} \mathrm{C}-\mathrm{RT}$

Scheme 3 Synthesis of thienyl substituted 1,2-oxathiine 2,2-dioxides

Attempts to effect the acid elimination of dimethylamine from 13d-open using increasing amounts of $4-\mathrm{TsOH}(0.05-5$ eq.) at either RT or reflux in PhMe were unsuccessful and at elevated temperature some yellowing of the reaction mixture was observed together the formation of minor amounts of polar 'degradation' material as indicated by TLC. The magnitude of the coupling constants between $3-\mathrm{H}$ and $4-\mathrm{H}\left({ }^{3} J_{3,4}=7.8-8.1 \mathrm{~Hz}\right)$ of the 3-phenyl substituted series 13a-open - 13d-open suggest that these protons occupy an anti-peri-planar arrangement. 
A crystal of 13a-open was obtained from $\mathrm{Et}_{2} \mathrm{O}$ and hexane (stored at $-20{ }^{\circ} \mathrm{C}$ for $24 \mathrm{~h}$ ) and an Xray crystal structure (Figure 1) confirmed the arrangement of 3-H and 4-H which have a torsion angle of $c a .39 .5^{\circ}$ with the torsion angle between the 3-Ph and 4-NMe $\mathrm{N}_{2}$ moieties as $78.9^{\circ}$. The $\mathrm{SO}_{2}$ unit of the oxathiine 2,2-dioxide ring protruded out of the main oxathiine ring plane $(\mathrm{O} 1$ $-\mathrm{C} 3-\mathrm{C} 4-\mathrm{C} 5-\mathrm{C} 6)$ with $\mathrm{C} 3-\mathrm{S} 2-\mathrm{O} 1$ angle of $c a .110^{\circ}$. The thiophene rings adopt an antiparallel conformation which favours the reversible photocyclistion process. ${ }^{1,2,37}$

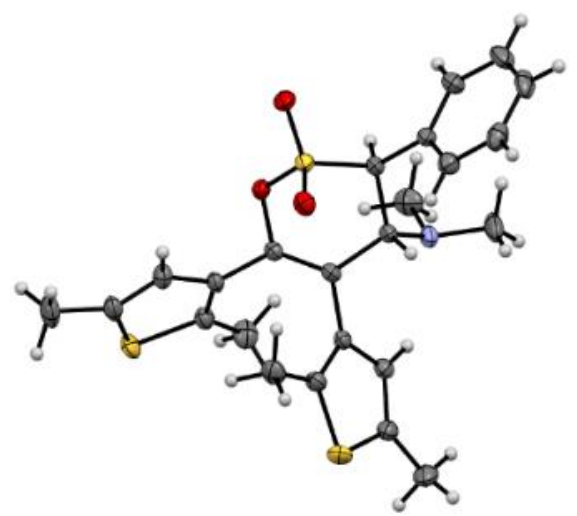

Figure 1 Crystal structure of 13a-open (thermal ellipsoids shown at $50 \%$ probability level and disordered $\mathrm{Et}_{2} \mathrm{O}$ solvent molecule omitted for clarity $)^{38}$

Given the syn-relationship between 3-H and the 4-NMe 2 moiety a Cope elimination protocol was adopted to affect the syn-elimination of the dimethylamine unit. ${ }^{39}$ Pleasingly, treating a DCM solution of 13d-open with an excess of $m$-CPBA $\left(0-5^{\circ} \mathrm{C} \rightarrow \mathrm{RT}, 4 \mathrm{~h}\right)$ afforded 14dopen $(\delta 4-\mathrm{H} 7.01)$ as pale-yellow crystals in $62 \%$ yield. Repeating this procedure enabled the isolation of 14a-open $(84 \%, \delta 4-\mathrm{H} 6.89)$, 14b-open $(78 \%, \delta 4-\mathrm{H} 6.89)$, 14c-open $(71 \%, \delta 4-\mathrm{H}$ $7.04)$ and 14e-open $\left(78 \%, \delta_{3-\mathrm{H}} 6.61, \delta_{4-\mathrm{H}} 6.90\left(J_{3,4}=10.2 \mathrm{~Hz}\right)\right)$ without the detection of any $\mathrm{S}$ oxidised products (Scheme 3 ). This facile elimination protocol provides an efficient strategy to form unsaturated 1,2-oxathiine 2,2-dioxides from the 4-dialkylamino substituted 3,4-dihydro1,2-oxathiine 2,2-dioxides which are easily obtained from sulfene additions to enaminoketones.

With the series of oxathiine 2,2-dioxides 13-open and 14-open to hand their photochromic response was examined. Irradiating hexane solutions of 13a-open, b-open, c-open and e-open revealed very weak to moderate yellow - orange colour development (Table 1) due to photoinduced ring closure (Scheme 4) with $\lambda_{\max }$ in the range 413 to $441 \mathrm{~nm}$ after prolonged irradiation to a steady state (ca. $145 \mathrm{~min}, \lambda_{\text {irr }}=260-380 \mathrm{~nm}, 150 \mathrm{~W}$ ) (Figure 2). ${ }^{1} \mathrm{H}$ NMR spectra for 13a-open before and after irradiation are provided in the ESI. The remaining 5,6diphenyl analogue 13d-open showed no photochromic response. 

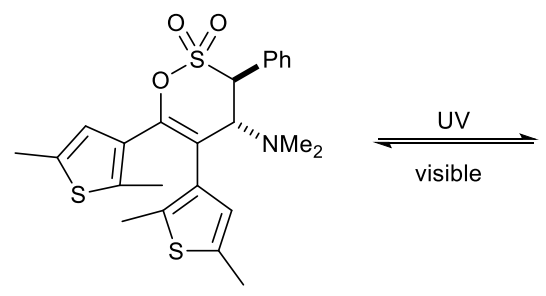

13a-open

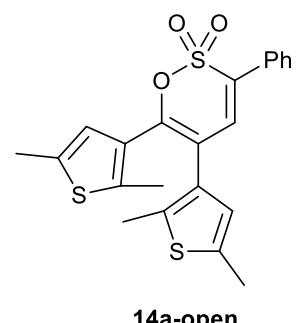

14a-open

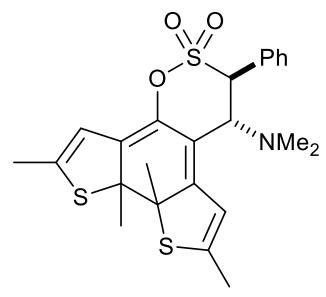

$13 a \cdot$ closed

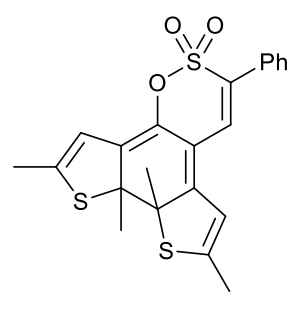

$14 a$ - closed

Scheme 4 Structures of 13a-open / 14a-open before and after irradiation

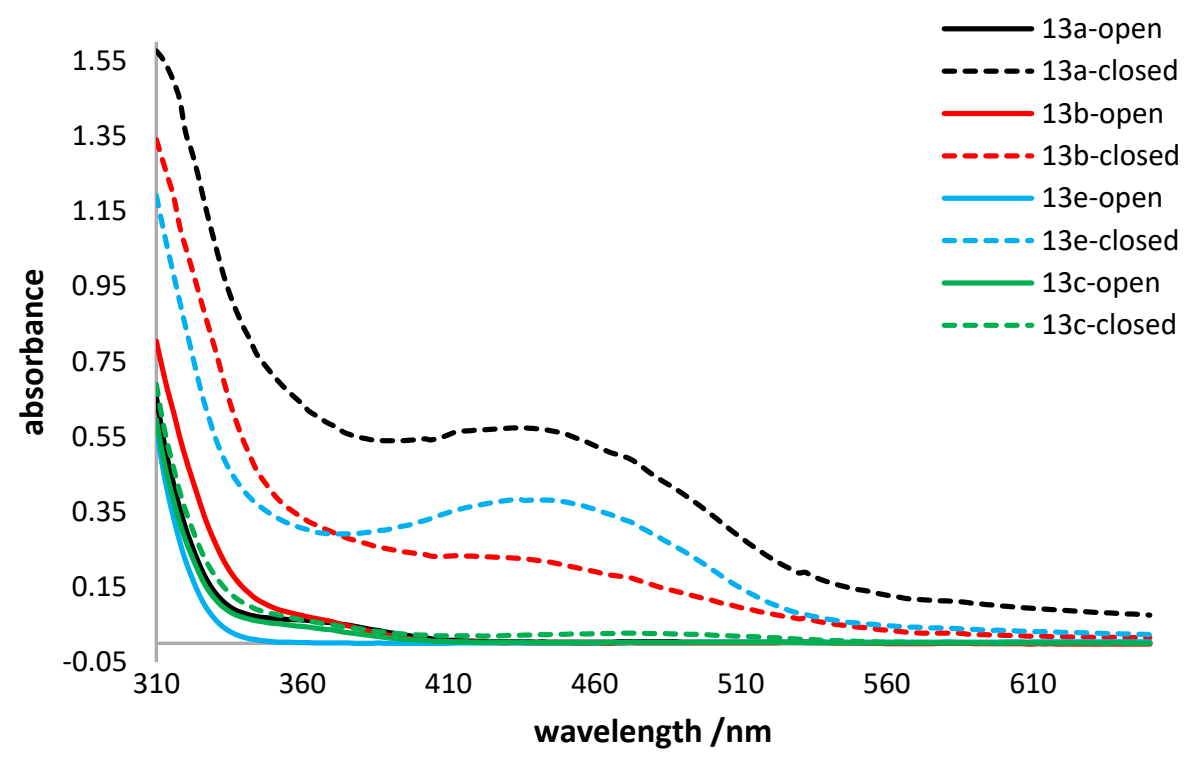

Figure 2 Absorption spectra (in hexane) of 3,4-dihydro-1,2-oxathiine 2,2-dioxides 13a-open, b-open, c-open, e-open before irradiation and at photostationary state

The photochromic behaviour of the unsaturated series 14a-open - e-open was next examined in hexane solution. Irradiation of a hexane solution of 14a-open resulted in the generation of an intense red hue ( $\lambda_{\max }=503 \mathrm{~nm}$, PSS $45 \mathrm{~min}$ ) (Figure 3 and insert 1, Table 1) which is assigned to the ring-closed isomer 14a-closed (Scheme 4). Visible light bleaching (455-650 $\mathrm{nm}$ ) of the foregoing red solution of 14a-closed was efficiently accomplished after 25 min. The colouration and bleaching of 14a-open (PhMe solution) was repeated 10 times to illustrate the reversibility of the system (insert 2 on Figure 3). 


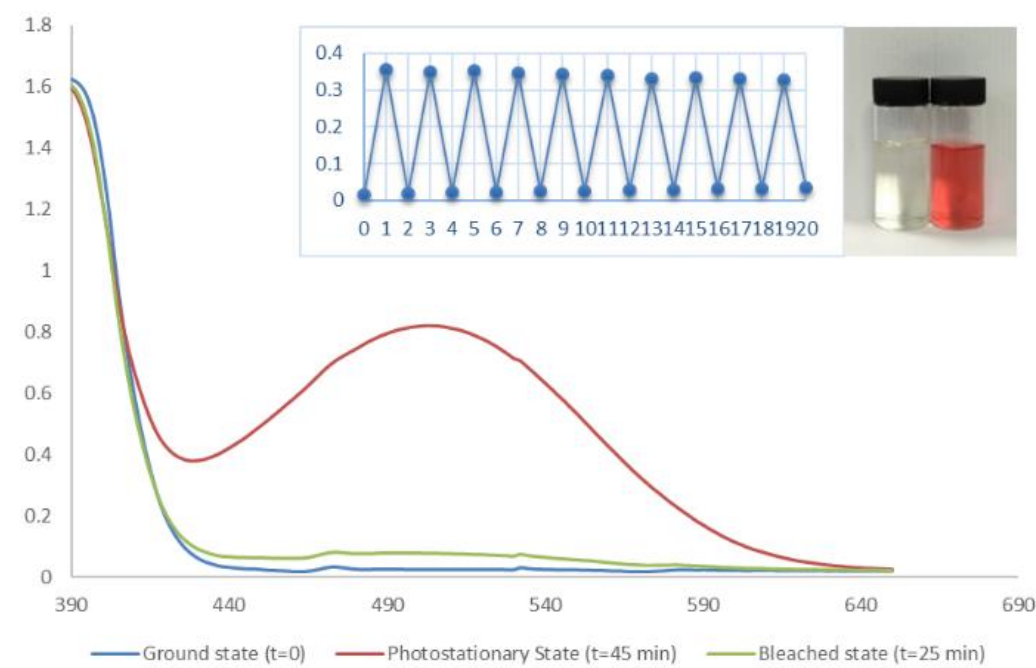

Figure 3 Absorption spectra of 14a-open (initial, after UV activation and after visible light bleaching); inset shows recyclability with UV activation and visible light bleaching cycles

Repeating the irradiation experiment of 14a-open in $\mathrm{CDCl}_{3}$ and recording the ${ }^{1} \mathrm{H} \mathrm{NMR}$ spectra over time revealed the presence of new signals attributed to 14a-closed at $\delta 2.05$ (Th-Me), 2.11 (Th-Me), 2.12 (Th-Me), 2.22 (Th-Me), 5.96 (Th-H) 6.07 (Th-H) and 6.83 (4-H) (Figure 4). Comparison of the integrals for 4-H in 14a-open $(\delta=6.89)$ and 14a-closed $(\delta=6.83)$ of the $\mathrm{CDCl}_{3}$ solution revealed a ratio of $c a .5: 3$ (14a-open/14a-closed) at the photostationary state (Figure 4, Table 1).

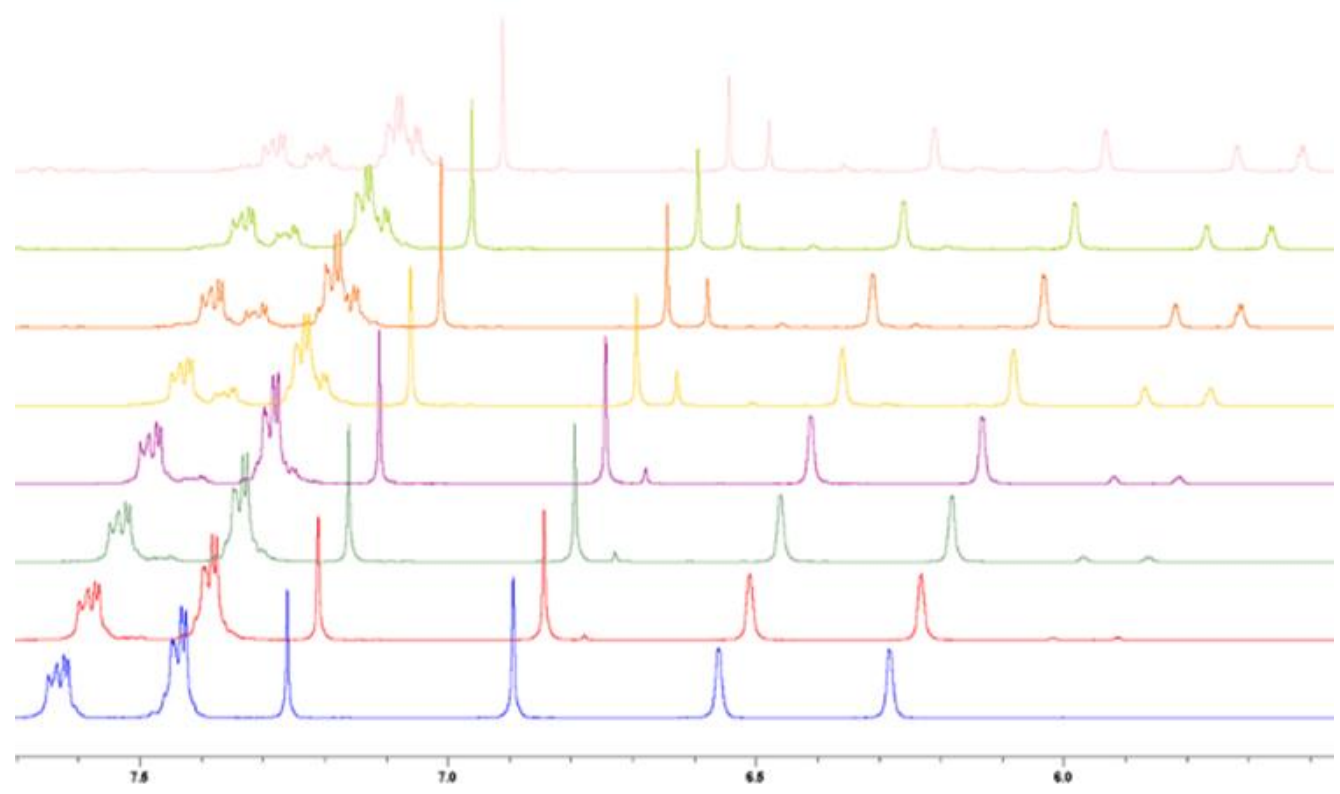

Figure $4{ }^{1} \mathrm{H}$ NMR spectra $\left(\delta 5.5-7.7, \mathrm{CDCl}_{3}\right)$ showing evolution of signals for photochemical ring-closure of 14a-open

Irradiation of 14e-open, similarly substituted with 2,5-dimethylthiophen-3-yl units, offered inferior performance to 14a-open with $\lambda_{\max }$ at $494 \mathrm{~nm}$ (50 min irradiation, ratio 14e-open:14eclosed $c a$. 10:1 based on the relative integrals of the doublets for $3-\mathrm{H}$ at $\delta 6.61$ (open) and $\delta$ 6.38 (closed) (see ESI for ${ }^{1} \mathrm{H}$ NMR spectra for 14e-open before and after irradiation). In the 
${ }^{1} \mathrm{H}$ NMR spectrum of 14e-closed signals were observed at $\delta 2.18,2.31,2.39$ and 2.64 for the methyl groups, at $c a . \delta 5.95$ for the thiophene ring protons and at $\delta 6.82(\mathrm{~d}, J=10.3 \mathrm{~Hz})$ for 4H. Unfortunately, 14b-open and 14c-open only showed an exceptionally weak red hue upon irradiation to generate their ring-closed forms (Figure 5) and the diphenyl analogue 14d showed no photochromism, emphasising the requirement for at least one 2,5-dimethylthiophene unit on the central ethene bond.

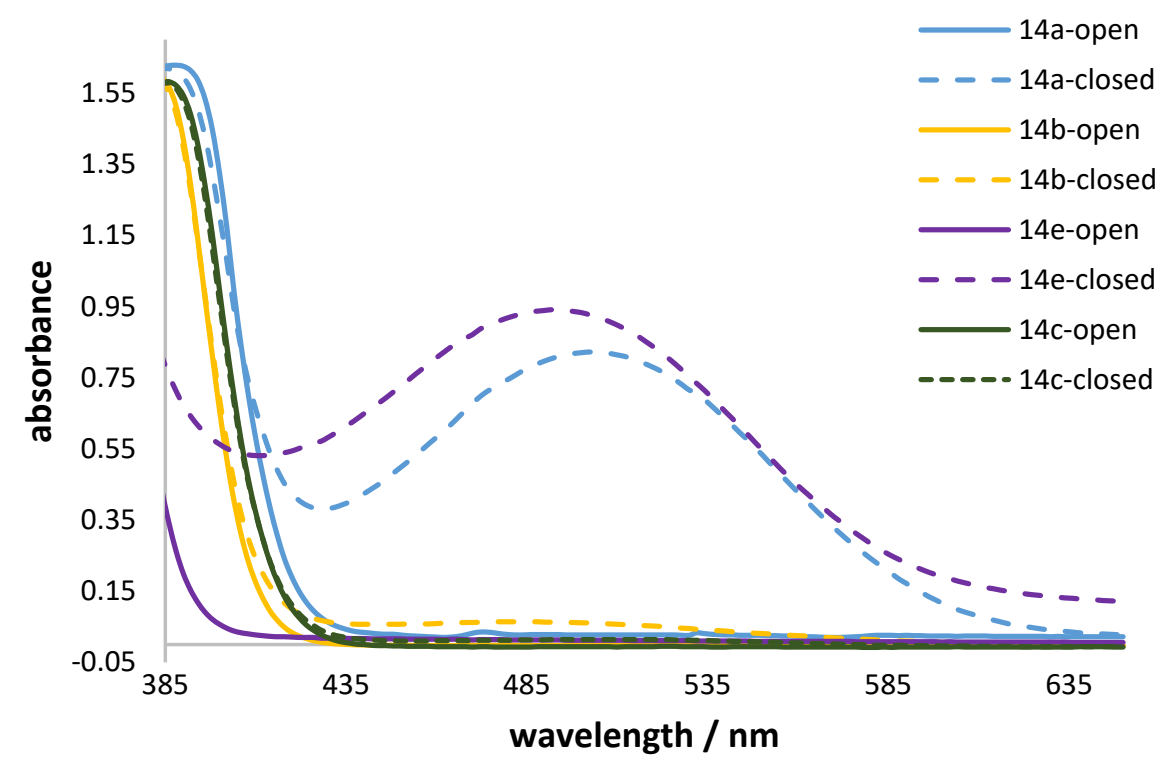

Figure 5 Absorption spectra (in hexane) of oxathiine 2,2-dioxides 14a-open, b-open, copen, e-open before irradiation and at photostationary state

Interestingly, the introduction of the C-3 - C-4 double bond induced a bathochromic shift in $\lambda_{\max }$ of 14a-closed $(503 \mathrm{~nm}$ ) and $\mathbf{1 4 e}$-closed $(494 \mathrm{~nm})$ relative to their dihydro precursors [13aclosed $(414 \mathrm{~nm})$, 13e-closed $(441 \mathrm{~nm})]$ presumably as a result of the extended lateral conjugation. It should be noted that the conjugation with the C-3 phenyl group (14a-open) resulted in the largest $(89 \mathrm{~nm})$ shift. The photochromic response of the series 13-open and 14open is summarised in table 1 .

\begin{tabular}{c|c|c|c|c|c|c|} 
& \multicolumn{2}{|c|}{$\lambda_{\max }(\mathrm{nm})^{\dagger}$} & \multicolumn{2}{|c|}{ Absorbance at $\lambda_{\max }{ }^{\ddagger}$} & $\varepsilon_{\mathrm{m}}$ at $\mathrm{PSS}^{\ddagger}$ & $\%$ closed form \\
& hexane & $\mathrm{A}_{0}$ & $\mathrm{~A}_{\mathrm{PSS}}$ & $\left(\mathrm{mol}^{-1} \mathrm{dm}^{3} \mathrm{~cm}^{-1}\right)$ & \\
\hline 13a-open/13a-closed & 414 & 0.01 & 0.55 & 1300 & 2 \\
\hline 14a-open/14a-closed & 503 & 0.03 & 0.82 & 1708 & 38 \\
\hline 13b-open/13b-closed & 413 & 0.01 & 0.23 & 489 & 5 \\
\hline 14b-open/14b-closed & 481 & 0.01 & 0.07 & 125 & 0.5 \\
\hline 13c-open/13c-closed & 474 & 0 & 0.03 & 61 & 2 \\
\hline 14c-open/14c-closed & 513 & 0 & 0.01 & 25 & 2 \\
\hline 13e-open/13e-closed & 441 & 0.01 & 0.38 & 1524 & 8 \\
\hline 14e-open/14e-closed & 494 & 0.01 & 0.94 & 1541 & 9 \\
\hline
\end{tabular}

Footnotes: ${ }^{\dagger}$ wavelength of maximum absorption of the closed species; ${ }^{\ddagger}$ absorbance $A_{0}$ before UV irradiation and absorbance Apss at photostationary state (PSS) for hexane solution of $c a .0 .5 \mathrm{mmoldm}^{-3}$; ${ }^{\ddagger}$ molar extinction coefficient of closed form at photostationary state as calculated using the Beer-Lambert Law; $\%$ closed form determined by comparison of the relative integrals of the signals for the thiophene ring methyl group protons in the original open forms and the closed forms at PSS. 


\section{Table 1: Photochromic response of series 13-open and series 14-open}

The solid-state photochromism of 14a-open was also briefly examined; with a powdered sample irradiated for $30 \mathrm{~s}$ with a TLC inspection lamp (Spectroline E Series $365 \mathrm{~nm}, 8 \mathrm{Watt}$ ). The change in appearance of the sample is clearly visible from the photograph presented in Figure 6 with the unirradiated sample appearing pale yellow and a post-irradiated sample developing a red / brown hue.

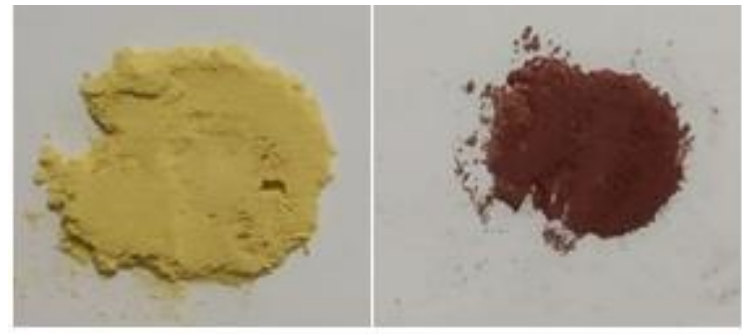

Figure 6: Photograph of 14a-open powdered sample on white paper background (LHS preirradiated, RHS post-irradiation)

In summary, 1,2-oxathiine 2,2-dioxides with combinations of aryl and heteroaryl substituents have been efficiently obtained for the first time by a Cope elimination protocol from their respective 4-dimethylamino-3,4-dihydro precursors which were derived from sulfene additions to enaminoketones. The 3,4-dihydro-1,2-oxathiine 2,2-dioxide series $\mathbf{1 3}$ exhibited very weak photo-colouration (low percentage ring closed form and hence weak molar extinction coefficients), perhaps due to limited activation as a consequence of a relatively low degree of unsaturation resulting in a low absorption in the activating UV region. Of the series $\mathbf{1 3}$ the 5,6bis(2,5-dimethylthien-3-yl) analogues 13a-open and 13e-open exhibited the best photochromism with UV irradiation generating their closed ring isomers which exhibited a weak yellow - orange hue. The series of unsaturated oxathiines 14 typically exhibited better photochromism then the dihydro precursors 13 . The oxathiine 2,2-dioxides 14a-open and 14eopen offered the best photochromism with $\lambda_{\max }$ of their closed ring forms bathochromically shifted relative to their dihydro-precursors, leading to moderately intense red-brown hues as a consequence of the extended lateral conjugation. The presence of a phenyl substituent on the oxathiine ring lead to a further small bathochromic shift in $\lambda \max v i z$. 14a-open $(503 \mathrm{~nm})$ and 14e-open (494 $\mathrm{nm}$ ). The photochromic response of 14a-open and 14e-open of this preliminary series of novel dithienylethenes containing a 1,2-oxathiine 2,2-dioxide core offered comparable performance to other heterocyclic bridged dithienylethenes. ${ }^{17-22}$ However, it is clear from this study that for good photochromic performance the presence of two substituted thiophene units at the termini of the central ethene bond combined with further unsaturation in the central oxathiine moiety is essential. ${ }^{1,2}$ Our exploration of the application of the oxathiine moiety as the central core in photochromic systems continues and is presently focussed on both further extending the lateral conjugation using substituted (hetero)aromatic systems and enhancing the photocolouration process.

$\dagger$ Electronic Supplementary Information (ESI) available: Experimental details and characterization data. CCDC 1905437 See DOI: 10.1039/x0xx00000x

\section{Acknowledgement}

DZ thanks the University of Huddersfield for funding for his $\mathrm{PhD}$ studies. 


\section{Conflicts of interest}

There are no conflicts to declare.

\section{Notes and references}

1. M. Irie, Chem. Rev., 2000, 100, 1685-1716.

2. M. Irie, T. Fukaminato, K. S. Matsuda, S. Kobatake, Chem. Rev., 2014, 114, 12174-12277.

3. D-K. Cao, J-S. Hu, M-Q. Li, D-P. Gong, X-X. Li, M. D. Ward, Dalton Trans., 2015, 44, 21008-21015.

4. D-P. Gong, T-B. Gao, D-K. Cao, M. D. Ward, RSC Adv., 2016, 6, 69677-69684.

5. S. Li, J. Tang, Y. Zhao, R. Jiang, T. Wang, G. Gao, J. You, Chem. Commun., 2017, 53, 3489-3492.

6. M. Yu. Belikov, Russ. J. Org. Chem., 2018, 54, 785-788.

7. N. M-W. Wu, M. Ng, W. H. Lam, H-L. Wong, V. W-W. Yam, J. Am. Chem. Soc., 2017, 139, 15142-15150.

8. J. C.-H. Chan, H-L. Wong, W-T. Wong, V. W-W. Yam, Chem. Eur. J., 2015, 21, 6936-6948.

9. C-L. Wong, C-T. Poon, V. W-W. Yam, Organometallics, 2017, 36, 2661-2669.

10. C-T. Poon, W. H. Lam, H-L. Wong, V. W-W. Yam, Chem. Eur. J., 2015, 21, 2182-2192.

11. J. C-H. Chan, W. H. Lam, H-L. Wong, N. Zhu, W-T. Wong, V. W-W. Yam, J. Am. Chem. Soc., 2011, 133, 12690-12705.

12. S. Pang, D. Jang, W. S. Lee, H-M. Kang, S-J. Hong, S. K. Hwang, K-H. Ahn, Photochem. Photobiol. Sci., 2015, 14, 765-774.

13. L. Bougdid, A. Samat, C. Moustrou, New J. Chem., 2009, 33, 1375-1361.

14. M. Cipolloni, F. Ortica, L. Bougdid, C. Moustrou, U. Mazzucato, G. Favaro, J. Phys. Chem. A, 2008, 112, 4765-4771.

15. F. Ortica, P. Smimmo, C. Zuccaccia, U. Mazzucato, G. Favaro, N. Impagnatiello, A. Heynderickx, C. Moustrou, J. Photochem. Photobiol. A, 2007, 188, 90-97.

16. M. M. Krayushkin, B. V. Lichitskii, A. P. Mikhalev, B. V. Nabatov, A. A. Dudinov, S. N. Ivanov, Russ. J. Org. Chem., 2006, 42, 860-864.

17. J. S. Park, T. T. Tran, J. Kim, J. L. Sessler, Chem. Commun., 2018, 54, 4553-4556.

18. M. M. Krayushkin, B. V. Lichitskii, D. V. Pashchenko, I. A. Antonov, B. V. Nabatov, A. A. Dudinov, Russ. J. Org. Chem., 2007, 43, 1357-1363.

19. M. M. Krayushkin, D. V. Pashchenko, B. V. Lichitsky, B. V. Nabatov, A. M. Komogortsev, L. G. Vorontsova, Z. A. Starikova, Russ. Chem. Bull. Int. Ed., 2008, 57, 2168-2174.

20. L. I. Belen'kii, A. V. Kolotaev, V. Z. Shirinyan, M. M. Krayushkin, Yu. P. Strokach, T. M. Valova, Z. O. Golotyuk, V. A. Barachevskii, Chem. Heterocycl. Compd., 2005, 41, 86-92.

21. K. P. Schultz, D. W. Spivey, E. K. Loya, J. E. Kellon, L. M. Taylor, M. R. McConville, Tetrahedron Lett., 2016, 57, 1296-1299.

22. S. N. Ivanov, B. V. Lichitskii, A. A. Dudinov, A. Yu. Martynkin, M. M. Krayushkin, Chem. Heterocycl. Compd., 2001, 37, 85-90. 
23. J. D. Hepworth, B. M. Heron, in 'Functional Dyes', Ed. S-H. Kim, Elsevier (Amsterdam), 2006, 85-135; J. D. Hepworth, B. M. Heron, Prog. Het. Chem., 2007, 17, 33-62.

24. S. Aiken, C. D. Gabbutt, B. M. Heron, C. S. Kershaw, N. J. Smith, J-P. Cano, US Patent, US 8,703,978 B2, (2014).

25. S. Aiken, K. Booth, C. D. Gabbutt, B. M. Heron, C. R. Rice, A. Charaf-Eddin, D. Jacquemin, Chem. Commun., 2014, 50, 7900-7903.

26. D. A. Clarke, B. M. Heron, C. D. Gabbutt, J. D. Hepworth, S. M. Partington, S. N. Corns, PCT Int. Appl., WO 9920630 A1, (1999).

27. M. Rickwood, J. D. Hepworth, C. D. Gabbutt, S. D. Marsden, Eur. Pat. Appl., EP 600669 A1, (1994).

28. S. Aiken, R. J. L. Edgar, C. D. Gabbutt, B. M. Heron, P. A. Hobson, Dyes Pigm., 2018, 149, 92-121.

29. S. Aiken, K. Anozie, O. D. C. C. de Azevedo, L. Cowan, R. J. Edgar, C. D. Gabbutt, B. M. Heron, P. A. Lawrence, A. J. Mills, C. R. Rice, M. W. J. Urquhart, D. Zonidis, Org. Biomol. Chem., 2019, submitted.

30. A. Bargagna, P. Schenone, F. Bondavalli, M. Longobardi, J. Heterocycl. Chem., 1980, 17, 1201-1206.

31. A. Bargagna, F. Evangelisti, P. Schenone, J. Heterocycl. Chem., 1981, 18, 111-116; F. Evangelisti, P. Schenone, A. Bargagna, J. Heterocycl. Chem., 1979, 16, 217-220.

32. A. Bargagna, P. Schenone, G. Bignardi, M. Longobardi, J. Heterocycl. Chem., 1983, 20, 1549-1552; G. Menozzi, A. Bargagna, L. Mosti, P. Schenone, J. Heterocycl. Chem., 1987, 24, 633-635.

33. L. Mosti, P. Scheneone, G. Menozzi, S. Cafaggi, J. Heterocycl. Chem., 1982, 19, 1031-1034.

34. B. Zwanenburg, in 'Science of Synthesis', Volume 27: Heteroatom Analogues of Aldehydes and Ketones, 27.3: Product Class 3: Thioaldehyde and Thioketone S,SDioxides and Oxyimides (Sulfenes and Derivatives), Ed., A. Padwa, Georg Thieme (Stuttgart), 2004, 123-134.

35. J. B. Press, J. J. Mcnally, J. Heterocycl. Chem., 1988, 25, 1571-1581; O. G. Karamov, V. P. Rybalkin, N. I. Makarova, A. V. Metelitsa, V. S. Kozyrev, G. S. Borodkin, L. L. Popova, V. A. Breń, V. I. Minkin, Russ. Chem. Bull., Int. Ed., 2011, 60, 168-174.

36. M. Nowak, Synlett, 2015, 26, 561-562.

37. M. Irie, K. Sakemura, M. Okinaka, K. Uchida, J. Org. Chem., 1995, 60, 8305-8309.

38. Crystal for 13a. Crystal data for $\mathrm{C}_{26} \mathrm{H}_{32} \mathrm{NO}_{3.50} \mathrm{~S}_{3}, M=510.70$, triclinic, $a=9.869$ (5), $b=$ 11.897 (5), $c=13.181$ (5) $\AA, \alpha=113.322$ (17), $\beta=109.14(2), \gamma=90.79$ (2) ${ }^{\circ}, V=1324.1$ (10) $\AA^{3}, T=150 \mathrm{~K}$, space group $P-1, Z=2,19176$ reflections measured, 8011 independent reflections $\left(R_{\text {int }}=0.0392\right)$. The final $R_{l}$ values were $0.0519(I>2 \sigma(I))$. The final $w R\left(F^{2}\right)$ values were $0.1309(I>2 \sigma(I))$. The final $R_{l}$ values were 0.0778 (all data). The final $w R\left(F^{2}\right)$ $=0.1481$ (all data). The goodness of fit on $F^{2}$ was 1.027. Peak and hole $=0.823 /-1.120$. CCDC 1905437 contains the supplementary crystallographic data for this paper. These data can be obtained free of charge from The Cambridge Crystallographic Data Centre via www.ccdc.cam.ac.uk/data_request/cif. The structure contained a disordered diethyl ether solvent molecule which was modelled in two positions using the PART instruction in the 
refinement. The anisotropic displacement parameters were restrained using the DELU and SIMU instructions.

39. P. C. Astles, Simon V. Mortlock, E. J. Thomas in 'Comprehensive Organic Synthesis', Elsevier (Amsterdam), 1991, vol 6., chap. 5.3, pp. 1011-1039. 